\title{
A semiótica visual de Emory Douglas na construção da identidade negra: movimento Black Panther e militância das comunidades afro-americanas.
}

Emory Douglas's visual semiotics in building the black identity: Black Panther movement and militancy of African-American communities

\author{
VALENTIN DA SILVA, Cláudio; Mestrando; UEMG
}

valentincs@gmail.com

APARECIDA DA CONCEIÇÃO RIBEIRO, Rita; Doutora; UEMG

rribeiroed@gmail.com

\section{Resumo}

Este artigo faz uma breve analise da importância da iconografia desenvolvida pelo designer, artista e ministro da cultura do partido dos Panteras Negras Emory Douglas para os movimentos sessentistas pela igualdade de direitos civis das comunidades afro-americanas e como ela estabeleceu uma simbiose entre as linguagens visuais semióticas alinhadas com as agendas da militância do partido. Propõe uma análise sobre como design perpassa a constituição dos movimentos de militância e desenvolve uma nova perspectiva de projeção do olhar para os sujeitos.

Palavras Chave: Design, linguagens visuais, ativismo, Panteras Negras.

\section{Abstract}

This article briefly reviews the importance of iconography developed by Emory Douglas Black Panthers' designer, artist, and culture minister to the sixties movements for equal civil rights of African-American communities and how it established the symbiosis between visual languages semiotics aligned as agendas of party militancy. An analysis of how design pervades the constitution of militant movements and develops a new perspective of the projection of the gaze to the subjects.

Keywords: Black Panthers, semiotics, design, Emory Douglas. 


\section{Introdução}

Falar sobre os legados simbólicos difundidos pelo partido dos Panteras Negras entre as décadas de 1960 e 1970, suscita diversas opiniões que vão desde os olhares apaixonados que enxergam os Panteras como lideres visionários que tentaram expandir a luta dos direitos civis afro-americanos em uma oportunidade para combater o imperialismo ocidental, o racismo global e a exploração capitalista dos trabalhadores e suscita também olhares em outro extremo, que consideram os militantes dos Panteras como um grupo de bandidos violentos, explorando condições opressivas para atender à suas agendas patológicas.

Este cenário de lutas pelos direitos civis dos cidadãos afro-americanos, teve uma iconografia própria que marcou o imaginário militante representando um "novo" negro, capaz de exigir seus direitos e romper com os papéis de subalternidade e que perpassa os movimentos de luta negra até os dias atuais. Estas representações gráficas foram amplamente difundidas nos EUA a partir das ações do partido dos Panteras Negras e impactaram a mídia e a indústria do entretenimento passando pela moda, a música e o cinema.

Segundo a pesquisadora Collete Gaitter (2005), entre o final da década de 1960 até meados dos anos 1970 o jornal periódico Black Panther, que era coordenado pelo designer Emory Douglas, em seu auge chegou a ter uma circulação semanal de 139.000 exemplares que eram distribuídos em bancas de jornais e universidades nos Estados Unidos. Suas ilustrações e pôsteres que trabalhavam com o imaginário de autoestima do negro eram afixados em edifícios abandonados nas cidades.

Em meio às indagações naturais da busca de entender porque o imaginário das lutas por direitos civis norte-americanos ainda influencia tantos grupos negros ao redor do mundo e mesmo vivendo em países como o Brasil, com uma constituição geográfica e cultural tão distinta dos norte-americanos, porque nos sentimos tão representados e tão movidos a pautas embrionadas num contexto de brutalidade tão específica deste povo?

O contexto de luta pela igualdade de direitos dos negros nos Estados Unidos, foi o embrião de uma identidade aguerrida e marcada por iconografias de valorização da cor e origens africanas. A força de suas mensagens é capaz de mudar a conotação do olhar das pessoas que se sentem inferiorizadas socialmente e de criar condições para um processo de valorização de suas origens. Reconhecendo que o design exerce um papel de reprodução dos valores culturais de um povo, dos códigos simbólicos e da representação material e de estilos de vida, este trabalho pretende fazer um breve estudo sobre os valores culturais e os códigos simbólicos que foram tensionados nos cartazes produzidos pelo designer Emory Douglas, responsável pelo desenvolvimento de toda a identidade visual e iconografia do movimento sessentista norte americano Black Panther Self Defense e que foram amplamente divulgados nos Estados Unidos, influenciando os estilos de vida e de expressão que vieram a ser reproduzidos na indústria do entretenimento quando se falava em lutas pelos direitos afro-americanos. 


\section{0 movimento Black Panther Self Defense}

Na cidade de Oaklan, California, em 1966 as comunidades afro-americanas sofriam com o abuso da violência policial. Para lidar com esta situação, os ativistas Huey Percy Newton (1942 1989) e Robert "Bobby" George Seale (1936) se uniram para criar uma organização extraparlamentar com a finalidade de proteger os residentes dos atos de brutalidade cometidos pela polícia.

Influenciados pelos ensinamentos do líder negro Malcolm $X$, pensadores de visão política de esquerda e pelos ecos midiáticos dos movimentos de Montgomery, inicia-se um novo olhar sobre a busca pela igualdade de direitos em que há uma mistura de paz, do confronto simbólico e físico, mas também a ideia de cuidado e zelo pela comunidade. "Nós usamos a "Pantera Negra" como símbolo porque na natureza as panteras não atacam ninguém, mas quando é atacada ela vai recuar, mas se o agressor continuar, atacando então ela ataca" (BLACK, 2015).

Newton era estudante de direito e, por conhecer a legislação local que definia que qualquer cidadão poderia fazer uso do porte de armas, desde que não tivesse um processo criminal, definiu que os integrantes do partido passariam a carregar armas de fogo de maneira visível nas ruas e também passariam a se organizar e seguir viaturas policiais mantendo uma distância legal como uma maneira de monitorar a polícia dos abusos que eram cometidos nas regiões periféricas da cidade. A comunidade afro-americana na cidade de Oakland, além de conviver com as leis de segregação racial também denunciava os abusos que eram cometidos pela polícia contra pessoas negras e que eram impunes na justiça. Segundo a Newton Foundation (2005) em 1966, após a aprovação da legislação dos direitos civis americanos, os guetos negros de Oakland tiveram taxas desproporcionais de desemprego, educação e saúde de qualidade inferior em relação às comunidades não negras. $O$ partido dos Panteras Negras trabalhou com a autoestima do negro que vivia papéis de subalternidade e agiu simbolicamente através do armamento do negro para a luta pelos direitos e também com programas de assistência social que mobilizavam os integrantes do partido para a alimentação de crianças negras antes de ir para a escola e outros processos de formação.

As ações do movimento despertaram a atenção da imprensa até que em 1967 em Sacramento, durante um evento onde participou o então governador da Califórnia Ronald Regan, cerca de 30 integrantes do partido que fizeram uma caravana até a cidade e tiveram destaque nacional.

\footnotetext{
“Estávamos no gramado do capitólio, e Regan estava lá, a cerca de três metros de nós em uma conferência de imprensa com jovens e crianças de uma escola paroquiana. Assim que a imprensa nos viu, gritaram de onde estavam os Panteras Negras" (NELSON, 2015).
}

As cenas do grupo entrando armados pela Câmara Legislativa, a ação policial coibindo o uso de armas, os gritos do grupo apelando para o respeito à Constituição e uma fala do governador se posicionando contrariamente às pautas do grupo, foram o gancho para a imprensa divulgar o nome do grupo e as causas por todo país. Isso atraiu novos simpatizantes pela causa negra (MUBARAK (2015). 
Com o recrutamento de negros que haviam sofrido brutalidade policial no dia a dia, o grupo cresceu rápido e chamou atenção de várias cidades. Abordando questões de moradia, bemestar e saúde, o ideário do grupo foi ao encontro dos anseios da população negra em todo o país. Com a filiação do escritor Eldridge Cleaver (1935 - 1998) como ministro de informação dos Panteras Negras, o movimentou ganhou mais notoriedade. Segundo CARSON (2015), Cleaver tinha credibilidade com os intelectuais negros e intelectuais brancos de esquerda.

Em 1968, Cleaver publicou uma coleção de ensaios escritos durante o ano de 1965 na Prisão Estadual de Folsom. O livro se chama "Soul on Ice", que foi uma das obras mais vendidas do ano, amplamente elogiado pela crítica e se tornou uma das mais importantes obras da literatura afro-americana. A narrativa descreve a transformação de um traficante em um revolucionário marxista adepto de Malcolm X.

O The Examiner fez uma reportagem no jornal dizendo que éramos "anti-brancos", que nós não tínhamos "papas na língua quanto a sermos anti-brancos". Isso é sensacionalismo mentiroso. Nós não odiamos ninguém por causa da cor. Nós odiamos a opressão. Nós odiamos o assassinato de pessoas negras em nossas comunidades (NELSON, 2015).

Os objetivos originários do partido eram baseados no combate à opressão das comunidades negras e promover avanços na luta pela igualdade de direitos. Uma nova leitura do sonho de igualdade entre negros e brancos que foi tão inspirada nos discursos de Martin Luther King Jr. Porém, o movimento agia estrategicamente com a intenção de promover a mudança simbólica da condição de subalternidade em que os negros se enxergavam, para o reconhecimento do seu poder de ação e cidadania. A partir da autovalorização do coletivo, criaram o seu próprio estilo de existência, e se apropriaram disso como direito a fortalecer sua própria forma de expressão. Munidos da convicção de estarem promovendo a vanguarda nas esferas política, artística e social, sem modéstia, ostentaram seus cabelos afros, suas boinas fazendo referências às lutas revolucionárias e suas jaquetas de couro. Refletiram um novo retrato para os negros dos anos 60 como novos modelos identitários de influência para os jovens que aspiravam por mudanças profundas no contexto social.

\section{A importância da obra do designer Emory Douglas}

Emory Douglas (1943), nasceu em Grand Rapids, Michigan, se tornou artista, designer, ilustrador e ministro da cultura no partido dos Panteras Negras em 1966. Compreendendo a emergente cultura da mídia visual, os líderes do partido Cleaver e Newton buscavam traduzir graficamente o trabalho do partido com as comunidades como uma forma de prepará-los para uma revolução violenta. Foi aos 22 anos que Douglas foi convidado para criar e manter a identidade da organização e produziu todas as edições do jornal Black Panther, que cessou em 1979. 
Figura 1 - Primeira edição do jornal Black Panther

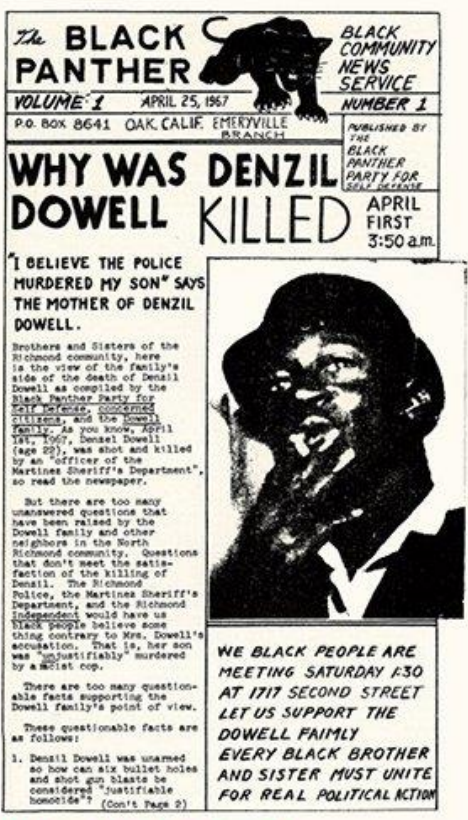

First issue of The Black Panther Center forthe Study of Polfican Graphics, Los Angeles)

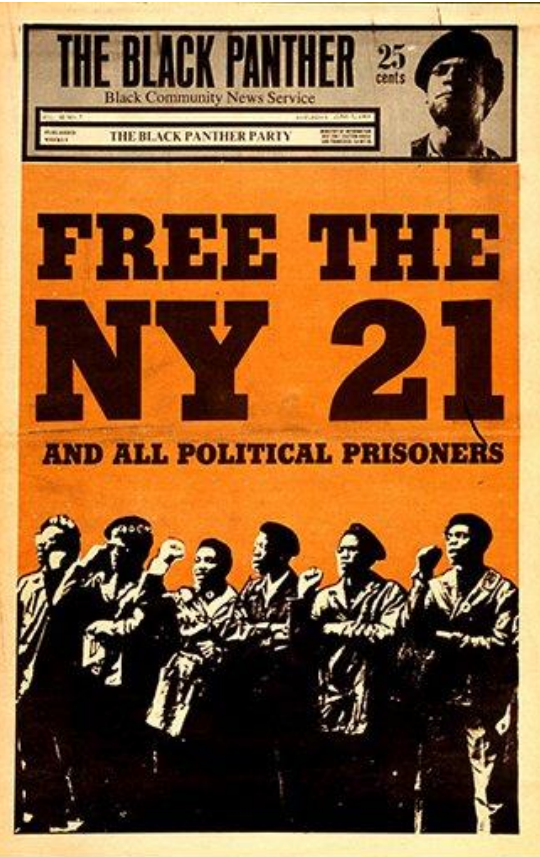

Volume 3, Number 7, June 7, 1969

Fonte: Arquivo AIGA (The Professional Association For Design)

$\mathrm{Na}$ adolescência Douglas foi sentenciado a quinze meses de reclusão em uma na escola de reabilitação para jovens (Youth Training School) em Ontario / Califórnia. Neste período de reclusão ele trabalhou na gráfica do programa e mais tarde estudou arte comercial em São Francisco. Quando conheceu o ministro da defesa do partido Huey Newton e o ministro da informação Eldridge Cleaver, ele se voluntariou a criar formas de fazer o recém-criado jornal ficar mais profissional.

Continuando com uma longa tradição de arte resistente e revolucionária, praticada simultaneamente em conflitos em todo o mundo, Douglas foi o agitador gráfico mais prolífico e persistente nos movimentos americanos do poder negro. Douglas profundamente entendia o poder das imagens em ideias comunicantes. O pôster da página de trás do jornal foi muitas vezes reimpresso separadamente, às vezes em cores (GAITER, 2005).

Utilizando técnicas de impressão como fotocópias, tipos móveis, texturas e padronagens, viabilizou a publicação semanal em formato tabloide em duas cores. Segundo Gaiter (2005) a estrutura econômica viável sistematizada por Douglas associadas a uma produção gráfica sedutora que reaproveitava materiais do desperdício em uma sociedade decadente se tornaram as armas da revolução. Através de técnicas de orçamento baixo Douglas trabalhava com recortes de fotografias e produzia imagens rápidas para cumprir com os prazos do jornal. Com combinações de texturas engenhosas desenvolveu seu estilo de ilustração que apresentava grossos contornos negros (mais fáceis de imprimir). 
Figura 2 - Série de Cartazes de Emory Douglas
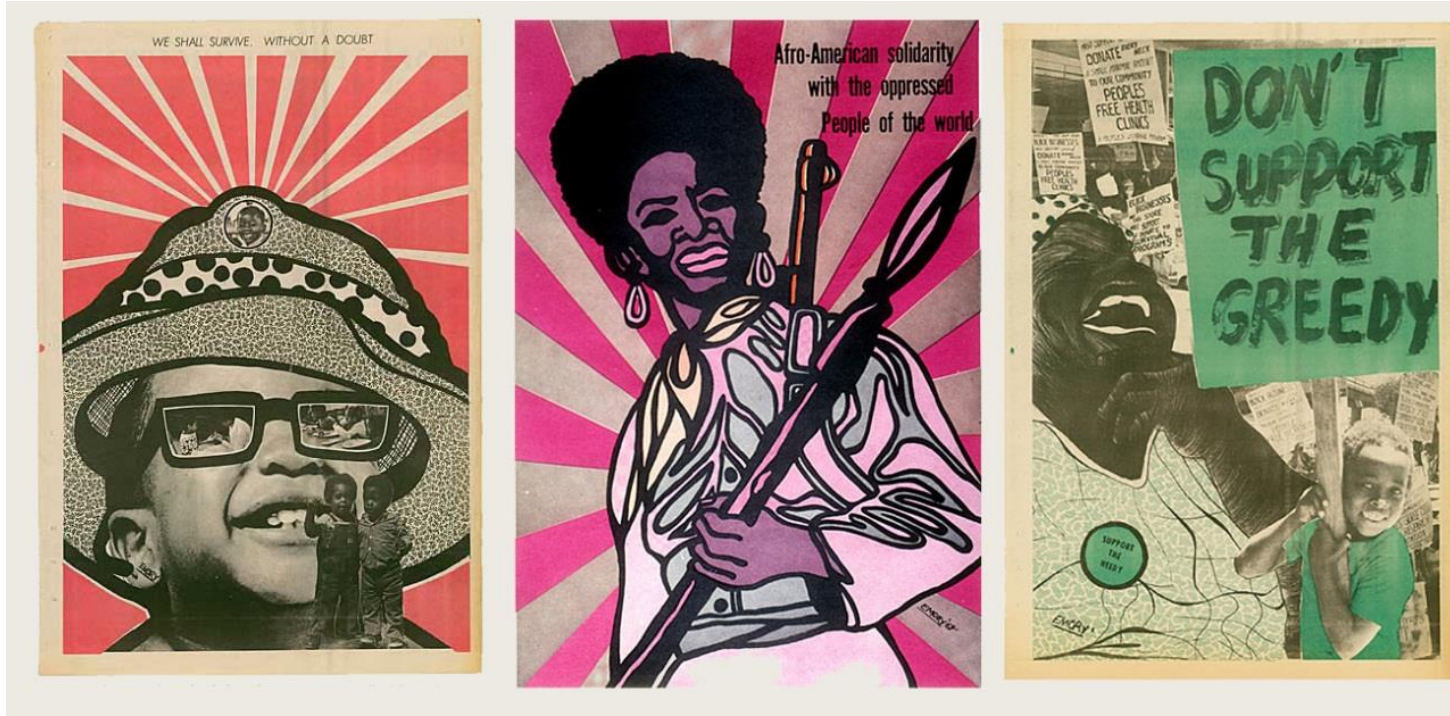

Fonte: Arquivo AIGA (The Professional Association For Design)

Conceitualmente Douglas, de forma ilustrativa, representava as condições que viviam os afro-americanos de Oakland e que despertava a necessidade de uma militância revolucionária e também constituía uma mitologia em do poder ao povo que havia sido oprimido.

\footnotetext{
A maioria das mídias populares representam as pessoas de classe média a alta como "normais". Douglas era o Norman Rockwell do gueto, concentrando-se nos pobres e oprimidos. Partindo do estilo social realista de retratar pessoas pobres, que podem ser percebidas como voyeuristas e condescendentes, os desenhos enérgicos de Douglas mostraram respeito e carinho. Ele manteve a dignidade dos pobres ao mesmo tempo que ilustra graficamente situações difíceis (GAITER, 2005).
}

Como uma ruptura das mídias tradicionais que até os dias de hoje representam a figura da classe média como o padrão a ser seguido, a produção visual de Douglas desenvolvia uma linguagem em que trabalhava com a autoestima das classes mais baixas, preparando-as para uma espécie de "emancipação" psicológica dos veículos de mídia pré-estabelecidos. Uma revolução que além da militância nas ruas também fazia política através da constituição do imaginário social. Assim sendo, a busca por fatos próximos da vida e todas as implicações decorrentes disto, tomam uma dimensão maior, aonde mesmo o ato aparentemente mais banal, serve como indicador de uma possível poética (BOURRIAUD, 2009).

Podemos dizer que a obra visual desenvolvida por Douglas baseada nos movimentos de luta pela igualdade nos Estados Unidos se configurou como uma alternativa de representação para seus integrantes e mais tarde, este sistema diferenciava seus adeptos para o mundo. Quando falamos em entender um sistema de representação, estamos dizendo sobre compreender como funciona um sistema simbólico e como este cria seus significados. E quando nos envolvemos com estes sistemas, como isto influencia a forma em que vemos e nos comportamos no mundo.

A representação, compreendida como um processo cultural, estabelece identidades individuais e coletivas e os sistemas simbólicos nos quais ela se baseia fornecem possíveis respostas às questões: Quem eu sou? O que eu poderia ser? Quem eu quero ser? (WOODWARD, 2000, p.17). 
Podemos então dizer que quando se cria um discurso ou um sistema de representação, possibilitamos as pessoas a expressar seus modos de vida para o mundo, a se posicionar politicamente, influenciamos suas decisões e outras características. A linguagem publicitária, a narrativa das novelas e as promoções de marketing, também são capazes de construir identidades. Como Woodward (2000) afirma "A mídia nos diz como devemos ocupar uma posiçãode-sujeito particular - o adolescente "esperto", o trabalhador em ascensão ou a mãe sensível".

A cultura molda a identidade ao dar sentido à experiência e ao tornar possível optar entre várias identidades possíveis, por um modo específico de subjetividade (Woodward, 2000, p.19). Desde o momento em que acordamos temos contato com uma variedade de representações simbólicas que a cultura nos oferece. Através dos sistemas simbólicos também entendemos a gravidade das divisões sociais, como grupos são excluídos e estigmatizados quando têm suas identidades contestadas. Poderíamos pensar em como, até hoje, o negro é representado na publicidade, por exemplo, onde não é raro ser associado à exploração do fetiche da sexualidade ou cumprindo papéis de subserviência ao chefe branco num processo de manutenção dos significados.

Maia (2009) entende que no âmbito cultural a identidade é um conjunto de características comuns com a qual grupos humanos se identificam, estabelecendo hábitos e imprimindo caráter a um conjunto de indivíduos. Neste sentido, poderíamos pensar que o design agiria formulando estas "características", tanto materializando artefatos produzidos para o consumo ou para a livre expressão de suas identidades, como também como um articulador semiótico das elaborações linguísticas.

Douglas (2005) declara que existia uma relação simbiótica entre o jornal e o partido que garantiram a força das mensagens. O partido tinha uma agenda de objetivos denominada como "Ten point plan" ${ }^{11}$ que incluíam a busca pelo pleno emprego para as comunidades, habitação digna, educação e cuidados com a saúde e o controle comunitário das tecnologias modernas.

Douglas utilizou da semiótica visual como uma arma de revolução interferindo em aspectos psicológicos de quem acompanhava o jornal. Segundo GAITER (2005) os líderes do partido acreditavam que o jornal The Black Panther não estava apenas informando notícias, mas causando mudanças radicais. Como os desenhos de Emory, o papel era uma ferramenta para a libertação, visualizando confrontações violentas com os opressores. Mostrando a realidade da vida nos guetos, o conteúdo impulsionava a ação metafórica de luta contra as opressões e autoajuda da sua comunidade e também, se necessário, o confronto armado.

Imagens criadas no calor das manifestações sessentistas formaram uma estética aguerrida em que os desenhos eram produzidos utilizando técnicas semelhantes ao entalhe da madeira na produção de gravuras. Potencializando a rigidez dos contrastes. Trabalhando com a composição de motivos que representavam a simbologia da revolução estruturando uma identidade combativa que convocava a comunidade para o enfrentamento físico e mental da condição de subalternidade. "Emory Douglas fazia questão de desenhar seus personagens usando o uniforme

\footnotetext{
${ }^{1}$ O Programa de Dez-Pontos (Ten point plan), é um conjunto de diretrizes para o Partido das Panteras Negras que declara seus ideais e formas de operação, uma "combinação de uma Declaração de Direitos e uma Declaração de Independência". (SELF DEFENSE, 2015)
} 
do partido - jaqueta de couro e boinas inspiradas em Che Guevara. Suas figuras em chave maniqueísta, eram vistas ou como vítimas maltrapilhas ou heróis messiânicos, armados até os dentes" (MARTI, 2017)

Figura 3 - Cartazes de Emory Douglas para o jornal Black Panther
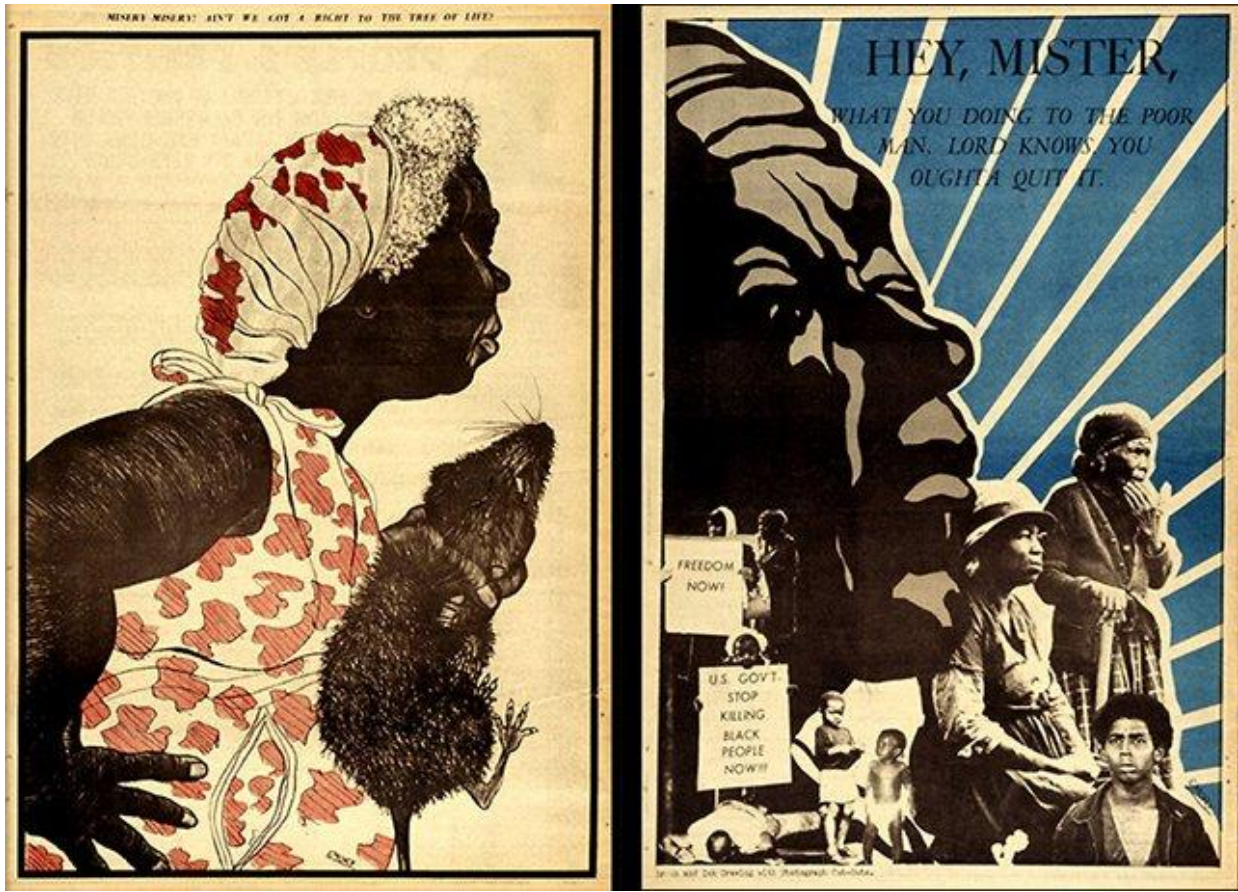

Fonte: Arquivo AIGA (The Professional Association For Design)

As ações do partido como alimentação gratuita para crianças, a criação de clínicas de saúde, escolas e eventos de arte foram representadas no papel como forma de ilustrar o estabelecimento da agenda de objetivos do partido. Isso criava uma perspectiva entre o imaginário de expectativas e das buscas militantes que eram a missão do partido, organizando as comunidades simpatizantes pelo programa.

Os líderes acreditavam que The Black Panther não estava apenas informando notícias, mas causando mudanças radicais. Como os desenhos de Emory, o papel era uma ferramenta para a libertação, visualizando confrontações violentas com os opressores percebidos. Os desenhos mostraram realidades brutais da vida de ghetto de direitos pósdireitos civis para afro-americanos. Incentivando a ação metafórica (luta contra a opressão através da auto-ajuda) ou física (confronto armado), as imagens mais severas de Douglas provocaram repulsa na violência gráfica e atração pela idéia de autodefesa efetiva (GAITER, 2005).

Douglas entendeu e usou efetivamente a semiótica visual antes que sua teoria e métodos fossem amplamente compreendidos e ensinados nos cursos de Design Gráfico. Exerceu seu papel de liderança como ministro da cultura do partido para agir na perspectiva simbólica da representação das pautas que a militância agia. À medida que a circulação do jornal crescia, também aumentavam os esforços do FBI para fechá-lo promovendo boicotes a pontos de venda e bloqueio da entrega de papel para a produção. 
Em 1970 J. Edgar Hoover, então diretor do FBI, declarou os Panteras como sendo a maior ameaça à segurança dos EUA. No ano anterior a infraestrutura do partido foi alvo de ataques resultando em 27 mortes de integrantes do partido e cerca de 749 prisões. As agências de aplicação da lei federal responderam atacando a organização através de COINTELPRO (propaganda de contra-espionagem), sabotagem e infiltração, contribuindo para a morte do partido.

\section{Considerações finais}

Do ponto de vista gráfico, Douglas foi o principal responsável na elaboração do imaginário de luta black que se espalhou pela indústria do entretenimento. Cunhou diversas iconografias que influenciaram outros movimentos da contracultura. Imagens criadas no calor das manifestações sessentistas formaram uma estética aguerrida em que os desenhos eram produzidos utilizando técnicas semelhantes ao entalhe da madeira na produção de gravuras. Potencializando a rigidez dos contrastes. Trabalhando com a composição de motivos que representavam a simbologia da revolução estruturando uma identidade combativa que convocava a comunidade para o enfrentamento físico e mental da condição de subalternidade.

O chamado de Douglas para a revolução, sob a forma de milhares de desenhos, desenhos animados e layouts de páginas, sobrevive como uma visão duradoura de capacitação. Até movimentos afro-americanos contemporâneos como o Black Lives Matter, que surgiu a partir da hashtag \#BlackLivesMatter em 2013 a partir da absolvição do segurança George Zimmerman após a morte a tiros do adolescente afro-americano Trayvon Martin. O movimento se tornou uma rede descentralizada sem hierarquias e estruturas formais que promove campanhas internacionais contra a violência direcionada aos negros. Mesmo manifestando alguns pontos de vista diferentes e despertando críticas de integrantes dos movimentos de 1960, usufruem da herança de toda a iconografia de luta consagrada pelos antigos e usufruem das mídias sociais para organizar protestos, denunciar abusos e debater o sistema criminal.

Deste modo, a cada momento da história, através do design e outras forças construtoras da realidade, a cultura estabelece mudanças na forma como a sociedade pensa, relacionase e apropria-se dos seus recursos naturais. (FARIA e MOURA, 2008, p. 2.).

O design é uma das disciplinas que mais contribuem para o desenvolvimento de valores intangíveis, por ser, em sua natureza, multidisciplinar e transversal. Como uma disciplina que está ligada à questão dos desejos humanos, busca encontrar processos para trabalhar melhor os sentidos e significados entre o homem e os produtos tangíveis e intangíveis.

O design perpassa nosso cotidiano, na forma em que nos expressamos para o mundo, na maneira que nos posicionamos politicamente, a forma que nos envolvemos com os produtos e nos relacionamos com as pessoas. Através dele atribuímos significados e ressignificamos tudo ao nosso redor. Experimentamos e moldamos nossas percepções sobre o mundo.

O modo como nos relacionamos passa por uma consciência de design. Desde a forma que nos vestimos, as nossas escolhas e maneira de se portar no mundo. Através dele torna-se possível a materialização cultural e a expressão indenitária. 
O design tem papel fundamental na construção e consolidação do imaginário social, através das nossas criações fazemos diversas associações simbólicas que perpassam o cotidiano das pessoas. Quando trabalhamos em um novo produto, desde a sua forma e elementos, comunicamos diversos significados que impactam modelos sociais.

Compreender as relações sociais que formam as bases das representações simbólicas da cultura black, nos ajudam a ter uma noção mais ampla sobre o papel do design na construção e transmissão deste imaginário. Expressando mitos urbanos, mudando a forma de as pessoas se enxergarem no mundo. Estas mudanças imateriais proporcionam transformações nas estruturas sociais, nos espaços públicos e na indústria cultural. Por isto é importante a compreensão contextual da atividade do design na articulação de valores culturais de diferentes grupos, estilos de vida, locais e globais.

O design, ao influenciar nosso cotidiano revela como experimentamos e moldamos nossas percepções sobre o mundo. Torna-se possível a materialização cultural, a expressão identitária e, por meio dele, podemos até mesmo dar "todo poder ao povo". 


\section{Referências}

BAUDRILLARD, J. (2006). O sistema dos objetos. São Paulo: Perspectiva.

BAUMAN, Z. (2001). Modernidade Líquida. Rio de Janeiro: Jorge Zahar.

BAUMAN, Z. (2005). Identidade. Rio de Janeiro: Jorge Zahar.

BOAS, A. V. (2009). Identidade e Cultura. Rio de Janeiro: 2AB.

BOMFIM, G. A. (2002). Seminário de Estudo e Pesquisa em Design. São Paulo: Universidade Anhembi Morumbi.

BONSIEPE, G. (2010). Cadernos de estudos avançados em design: Identidade. Belo Horizonte: UEMG.

CLEAVER, k. (1968). Acesso em 10 de Fevereiro de 2017, disponível em https://www.youtube.com/watch?v=SUdHf6nqL9U

FARIA, J. N., \& MOURA, M. (2008). Design e cultura contemporânea: a formação dos objetos culturais. Acesso em 5 de Maio de 2017, disponível em http://wright.ava.ufsc.br/ alice/conahpa/anais/2008/conahpa2008.zip\%20Folder/artigos/Design_ e_cultura_contemporanea_a_formacao_dos_objetos_culturais.pdf

GAITER, C. (08 de Junho de 2005). Visualizing a Revolution: Emory Douglas and The Black Panther Newspaper. Acesso em 13 de Agosto de 2017, disponível em AIGA - The Professional Assossiation for Design: https://www.aiga.org/visualizing-a-revolution-emory-douglas-and-the-black-panthernew

HALL, S. (2000). A identidade cultural na pós-modernidade. Rio de Janeiro: DP\&A.

HALLEY, A. (1965). Autobiografia de Malcolm X. Trad. A. B. Pinheiro de Lemos. Rio de Janeiro: Record.

Hudson, R. (Diretor). (2002). MIGHTY Times: the legancy of Rosa Parks [Filme Cinematográfico].

MARTI, S. (28 de Março de 2017). Mostra revê obra de Emory Douglas, guru visual dos Panteras Negras. Acesso em 4 de Abril de 2017, disponível em Folha de São Paulo: http://www1.folha.uol.com.br/ilustrada/2017/03/1870288-mostra-reve-obra-de-emory-douglasguru-visual-dos-panteras-negras.shtml

MAUSS, M. (2003). Ensaio sobre a dádiva. Forma e razão da troca nas sociedades arcaicas. São Paulo: Cosac Naify.

MOCELLIM, A. (2008). A questão da identidade em Giddens e Bauman. Santa Catarina: Revista Eletrônica de Pós-Graduandos em Sociologia Política da UFSC.

MOCELLIM, A. (2008). A questão da identidade em Giddens e Bauman. Santa Catarina: Revista Eletrônica de Pós-Graduandos em Sociologia Política da UFSC. 
MORAES, D. (1997). Limites do design.2.ed. São Paulo: Stúdio Nobel.

NELSON, S. (Diretor). (2015). Black Panther Vanguard of Revolution [Filme Cinematográfico].

SANTOS, M. C. (2008). Consumo, descarte, catação e reciclagem: notas sobre design e multiculturalismo. Acesso em 18 de Maio de 2017, disponível em Closchiavo: http://www.closchiavo.pro.br/pdfs/multiculturalismo_loschiavo.pdf

SELF DEfenSE, B. P. (2015). A Huey P. Newton Story. Acesso em 10 de dezembro de 2017, disponível em PBS: http://www.pbs.org/hueypnewton/actions/actions_platform.html

SILVA, T. T., HALL, S., \& WOODWARD, K. (2005). Identidade e diferença: A perspectiva dos estudos culturais. Rio de Janeiro: Editora Vozes.

SZATMARY, D. P. (2014). Rockin' in Time. Nova Jersey: Pearson.

VALLEN, M. (21 de Fevereiro de 2005). Black Panther Artist: Emory Douglas. Acesso em 27 de Outubro de 2017, disponível em Art for a Change: http://art-for-achange.com/blog/2005/02/black-panther-artist-emory-douglas.html 